\title{
EXPLICAÇÕES: MODOS DE REGULAÇÃO DE UMA ATIVIDADE GLOBALIZADA
}

\author{
ANTÓNIO NETO-MENDES
}

amendes@ua.pt

\section{JORGE ADELINO COSTA}

jcosta@ua.pt

\section{ALEXANDRE VENTURA}

alexandre.ventura@ua.pt

Departamento de Ciências da Educação da Universidade de Aveiro - Portugal

\section{RESUMO}

Neste artigo analisamos os modos de regulação de uma atividade - as explicações - que é hoje um caso de sucesso em todo o mundo como oferta educativa privada e que podemos mesmo considerar paralela à do modelo escolar. Num primeiro momento, procedemos à caracterização das políticas de regulação em escala global: a situação nos países que ignoram a atividade das explicações; o caso dos países que escolheram a via da proibição, total ou parcial; o caso dos países que reconheceram a atividade e até formularam políticas educacionais que encontraram nas explicações um aliado para a melhoria dos resultados escolares. Abordaremos depois a situação em Portugal, país onde a atividade existe desde há muito, mas que conhece na atualidade um vigor novo e maior visibilidade social. Quanto às políticas de regulação das explicações em Portugal, podemos falar de uma regulação burocrática sem grande eco na prática dos profissionais, dos estudantes e das famílias. Terminaremos com algumas reflexões sobre a necessidade de se dar dimensão pública à discussão sobre a atividade das explicações, tantas e tão sérias são as suas repercussões sociais e políticas, nomeadamente em matéria de democratização do acesso e do sucesso escolares, questão nuclear que está no cerne da preocupação com a equidade no seio das políticas públicas.

EXPLICAÇÕES - MERCADO DA EDUCAÇÃO - REGULAÇÃO - POLÍTICAS EDUCACIONAIS

\section{ABSTRACT}

PRIVATE TUTORING: WAYS OF REGULATION OF A GLOBALIZED ACTIVITY. In this text we analyze the ways of regulation of private tutoring, an activity that is at present a success story as a private educational product with an widespread use across the world that we can even see as

Trabalho desenvolvido no âmbito do projeto de pesquisa, intitulado "Xplika: o mercado das explicações, a eficácia escolar e o sucesso dos alunos", financiado pela Fundação para a Ciência e Tecnologia e pelo Programa Operacional Ciência e Inovação 20 I 0. Sítio do projeto: http://www2. dce.ua.pt/xplika/default.asp/ 
parallel to that of the school model. Firstly, we will characterize the regulation policies that are in place worldwide: $i)$ the situation of the countries that ignore the activity of private tutoring; ii) the case of the countries that have chosen to prohibit private tutoring, totally or partially; iii) the case of the countries that have recognized the activity and that have even developed educational policies that have found in private tutoring an ally in the improvement of school results. We will then discuss the situation in Portugal, a country where the activity has a long history, but that knows nowadays a new vigor and greater social visibility. In what concerns the regulation policies of private tutoring in Portugal, we can talk about a bureaucratic regulation without a great impact on the practices of education professionals, students and families. We will conclude our text with some reflections on the need to give public dimension to the discussion on the activity of private tutoring, as it has many and serious social and political repercussions, namely with respect to the democratization of school access and success, a main issue that is at the heart of the concern with equity in public policies.

PRIVATE TUTORING - EDUCATION MARKET - REGULATION - EDUCATIONAL POLICIES

As explicações (aulas particulares e reforço escolar no Brasil, private tutoring, em inglês; clases particulares, em castelhano; cours particuliers em francês) são um fenômeno social de grandes repercussões, em escala global (Costa et al., 2007). Muitas vezes é conferido a este fenômeno o estatuto do que em jornalismo se considera uma "não-notícia", sendo apresentado como "um sistema educativo na sombra" (the shadow education system) (Bray, 1999) ou como "uma atividade na sombra" (Costa, Ventura, Neto-Mendes, 2003).

Da afirmação anterior não se deve inferir que os agentes mais diretamente envolvidos - pais/estudantes e professores/explicadores - não valorizam suficientemente as explicações. Bastaria olhar o extraordinário sucesso que teve e continua tendo a atividade para desmentir tal pressuposto: entre os pais e os estudantes porque vêem nelas fundamentalmente um recurso que potencializa o sucesso nos exames e o ingresso numa formação escolar (de nível superior, mas não só) de prestígio; entre os professores/explicadores porque pode ser uma oportunidade de melhorar o salário (referimo-nos aos que exercem a atividade em tempo parcial, que são também professores no sistema regular de ensino) ou de assegurar trabalho, seja em tempo parcial ou em tempo integral (em regime de auto-emprego ou como assalariado num centro de explicações).

A relativa invisibilidade a que remetem as expressões acima tem a ver sobretudo, na nossa opinião, com os dois fatores que examinaremos em seguida: a pouca importância atribuída, nos meios acadêmicos, ao tema das 
explicações, traduzida na quase ausência de pesquisar e publicações a respeito, situação que nos propusemos rebater quando da concepção e apresentação do projeto'; a cortina de silêncio que, em alguns países, foi sendo construída e tolerada em torno da atividade das explicações, sobretudo por parte tanto das autoridades educacionais quanto dos professores e de suas associações representativas.

É parcialmente nesta última dimensão que queremos centrar nossa análise: como os governos encaram a atividade das explicações que tem claras repercussões acadêmicas (influência nos resultados escolares), sociais (a forma como determina, por exemplo, a organização do tempo familiar), econômicas (enormes quantias envolvidas)? Ignoram a atividade ou têm procurado discipliná-la de alguma forma? Reconhecem sua utilidade social, procuram até incentivá-la, ou pura e simplesmente relegam-na ao estatuto de "fruto proibido", condenando-a à clandestinidade?

Procuraremos responder a essas questões, propondo, de início, uma visão panorâmica do que tem sido feito em quase todo o mundo, para depois nos centrarmos na situação em Portugal, realidade que vem merecendo a nossa atenção nos últimos anos.

\section{POLÍTICAS DE REGULAÇÃO DAS EXPLICAÇÕES: ALGUNS CASOS PARA UMA APRECIAÇÃO GENÉRICA}

Importa ter presente que a análise da complexidade do fenômeno das explicações, mesmo sob o prisma das políticas de regulação, obriga a equacionar um conjunto de dimensões nem sempre devidamente avaliadas: os fatores que estão na origem quer da oferta quer da procura; as características que a atividade pode assumir e que estão estreitamente correlacionadas com o regime político, a economia, a cultura, o sistema de ensino; as representações sociais sobre a qualidade do ensino nas escolas e sua relação com as explicações, entre outros aspectos, direta e indiretamente relacionados com os anteriores.

Iniciaremos esta abordagem esclarecendo o que se entende aqui por políticas de regulação: referimo-nos ao posicionamento adotado pelos gover-

I. Referimo-nos ao Projecto Xplika. 
nos dos diferentes países em face do fenômeno das explicações -, quando este é uma realidade. Nesta matéria, constatamos que há uma considerável diversidade de políticas e de práticas, de acordo com alguns dos estudos mais conhecidos e que mencionaremos a seguir. Adaptando a proposta de Hallak e Poisson (2004), apresentamos uma divisão dos países em três categorias de acordo com a forma de conceber as políticas de regulação das explicações:

- países que ignoram a atividade das explicações;

- países que escolheram a via da proibição, total ou parcial;

- países que reconheceram a atividade e até formularam políticas educacionais que vêem as explicações como um aliado para a melhoria dos resultados escolares.

Hallak e Poisson (2004) explicam que os países que ignoram as explicações, como por exemplo Canadá e Japão, fazem-no por múltiplas razões: porque seus governos não conseguem lidar com as explicações; porque não querem agir em relação a estas; ou porque não se consideram responsáveis pelo fenômeno, seja porque o setor tem pouca expressão, seja porque, na sua ótica, ele deveria ser regulado pelas forças do mercado.

O segundo grupo (pouco numeroso, o dos países que escolhem a via da proibição) inclui a Coréia do Sul, que tentou proibir, sem sucesso, o recurso às explicações. Segundo Lartigue (2006), as explicações foram banidas do país no início da década de 1980 e a proibição vigorou até 2000, quando foi declarada inconstitucional por atentar contra os direitos básicos das famílias na educação das crianças. Além da proibição total e absoluta, há ainda a via das proibições parciais, resultantes, de qualquer forma, de uma orientação política que privilegia o reconhecimento da atividade e que procura assegurar-lhe alguma forma de enquadramento: falamos das restrições que contemplam um determinado nível de ensino (casos das Ilhas Maurícias e de Hong Kong), determinados dias ou horários (Taiwan), ou que impedem os professores de exercer a atividade quando estão envolvidos seus próprios alunos (Quénia, Bósnia-Herzegovina, Croácia, Polônia - em Portugal vai-se um pouco mais longe ao estender-se a proibição aos alunos das escolas onde os professores lecionam).

Saliente-se, a este propósito, que a publicação de leis e de normas como tentativa de regulamentação denota uma inequívoca intenção, por parte dos 
governos, de ter um papel ativo na regulação 2 . Pode-se discutir, como lembram Hallak e Poisson (2007, p.268), o alcance e o detalhe da regulação (limite máximo de horas por semana ou de número de alunos por grupo; especificação mais ou menos rigorosa dos requisitos exigidos dos centros de explicações/ explicadores, quanto a espaço, segurança e salubridade, qualificações dos explicadores, conteúdos curriculares e materiais, preços etc.). Sabemos, até por experiência própria, que o Estado pode implementar formas de regulação diversas que podem ir muito além da dimensão "escolar" propriamente dita. É o caso, por exemplo, da prestação de contas, no sentido mais literal, procurando retirar esta atividade da informalidade contábil e fiscal que a caracteriza, total ou parcialmente, em muitos países.

As intervenções governamentais com impacto nas explicações não se limitam à aplicação de leis que visam disciplinar a atividade. Uma parte significativa das repercussões resulta, em alguns países, de políticas educacionais que colocam os centros privados de explicações a serviço de medidas de discriminação positiva. Esse tipo de intervenção, embora assuma formas muito diversas nos sistemas escolares mundiais, visa essencialmente uma população que, por razões socioculturais e econômicas, é considerada escolarmente menos equipada. Essa faceta da análise não pode ser esquecida pois, nos contextos em que é adotada, procura responder às preocupações de eqüidade e justiça, dimensões a que as sociedades civis mais fortes e organizadas atribuem grande importância.

Hallak e Poisson (2007, p.269) mencionam que em Cingapura, por exemplo, o Estado financia centros privados que desenvolvem programas de reforço para estudantes oriundos de estratos socioeconômicos baixos. Nos Estados Unidos, o programa No Child Left Behind [Nenhuma criança é deixada para trás] apresenta medidas semelhantes que, de certa forma, contribuíram, segundo alguns autores, para o aumento do número de centros de explicações e de suas receitas, especialmente no caso das franquias mais conhecidas ${ }^{3}$.

O No Child Left Behind Act, assinado pelo presidente George W. Bush em 2002, apresenta-se como um plano ambicioso que pretende melhorar os

2. Sobre os conceitos de "regulação" e "regulamentação", ver o nosso trabalho Neto-Mendes (2004).

3. Sobre a dimensão das empresas franqueadas na atividade das explicações, ver Neto-Mendes et al. (2007). 
resultados acadêmicos dos estudantes das escolas públicas. Segundo Primont e Domazlicky (2006, p.77), esse programa dá ênfase à avaliação dos resultados de escolas e dos estudantes mediante a realização de testes padronizados. As escolas comprometem-se a realizar progressos anuais quanto aos resultados dos seus alunos sob pena de sanções. Aquelas que, pelo segundo ano consecutivo, não atingirem os progressos previstos devem liberar os alunos para escolherem outras escolas e pagar seus custos de transporte. No terceiro ano consecutivo sem cumprir os objetivos, as escolas são obrigadas a promover serviços educativos suplementares (supplemental educational services, que consistem no apoio em leitura e matemática) de acordo com a escolha dos pais e em colaboração com as autoridades educacionais.

Os diferentes governos estaduais escolhem um conjunto de centros de explicações (públicos e privados) e contratam com eles a prestação do serviço. Constituída a cesta dos fornecedores de explicações, a administração notifica os pais sobre a oferta e estes podem fazer suas escolhas. Segundo Boehner (2005), citando o Departamento Federal de Educação, foram aprovados mais de 1.600 prestadores de "serviços educativos suplementares" desde que o programa No Child Left Behind foi implantado. Cerca de três quartos pertencem à iniciativa privada e o restante surgiu no âmbito do sistema público de ensino.

Este é, sem dúvida, o caso de uma decisão política que teve um impacto muito profundo sobre o mercado das explicações: a injeção de dinheiro público (o mesmo Boehner citado antes fala de I,7 bilhões de dólares) e a promoção de uma política de liberdade de escolha do prestador do "serviço educativo suplementar" contribuíram decisivamente para o fortalecimento da indústria de explicações. Ela já ressalta a decisão dos poderes públicos no mais alto nível de conferir aos centros de explicações (a maioria de iniciativa privada) o estatuto de assessoria externa visando fundamentalmente promover os bons resultados dos alunos nos exames nacionais.

\section{AS EXPLICAÇÕES EM PORTUGAL: ASPECTOS ESSENCIAIS DA REGULAÇÃO}

A prática das explicações, como acabamos de ver, tem sido objeto de alguma atenção por parte das autoridades políticas nos mais diversos quadrantes políticos e geográficos. 
Portugal não foge à regra, como veremos a seguir, acompanhando outros países na adoção de medidas destinadas a controlar o exercício da atividade das explicações, em particular no que diz respeito aos profissionais (chamados de explicadores). Esses profissionais são, de fato, quase sempre professores em uma de duas situações: trabalham part time como fornecedores de explicações (individualmente ou em uma empresa, de pequena ou média dimensão, conhecida como "centro de explicações" ou "centro de estudos"), tendo como atividade principal a de professores numa escola pública ou privada; trabalham em tempo integral na chamada "indústria das explicações". Essa atividade sempre existiu, mas teve nos últimos anos um crescimento considerável devido, entre outras razões, ao aumento da mão-de-obra qualificada disponível constituída por profissionais que têm licenciatura, mas que não encontram trabalho no sistema de ensino regular.

Apesar de haver indícios de que está aumentando o número dos que se dedicam às explicações com exclusividade, pelas razões que apontadas, tradicionalmente o corpo de explicadores era (e pensamos que continua a ser) recrutado predominantemente entre os professores do ensino regular.

Em Portugal, por razões históricas, políticas e culturais, o ensino regular situa-se de forma amplamente majoritária na esfera do Estado: o chamado "ensino público" era responsável por empregar, em 2006/2007, cerca de 84\% dos professores do ensino não superior em atividade, cabendo ao "ensino privado" os restantes $16 \%$, proporção que se tem mantido estável mesmo com as alterações dos totais de docentes contratados nos dois subsistemas ${ }^{4}$.

Não surpreende, portanto, que uma parte significativa dos explicadores em Portugal seja recrutada entre os funcionários do Estado: a docência na escola pública é a sua atividade principal (estando sujeitos a um regime de exclusividade determinado pelo estatuto da carreira docente), enquanto as explicações são uma atividade realizada, pelo menos para uma boa parte dos trabalhadores,

4. Em 2006/2007, de acordo com as estatísticas oficiais, há 142.384 professores no ensino público e 27.628 no ensino privado. Disponível em: http://www.giase.min-edu.pt/content02. asp?auxID=pubs-online\#dadosglobais (acesso em: 20 mar. 2007). Esses números revelam uma redução de cerca de 8 mil efetivos quando comparamos com a situação relativa ao ano letivo 2005/2006: trabalhavam nas várias tipologias da escola pública I 49.844 docentes (cerca de $84 \%$ ) e na escola privada 28.358 (cerca de 16\%), o que perfaz um total de 178.202 profissionais docentes (disponível em: http://www.giase.min-edu.pt/IndSintese0506.asp; acesso em 23 mar. 2006). 
em part-time ${ }^{5}$, num regime de exercício privado de uma atividade que para todos os efeitos é "paradocente".

Ainda assim, não podem ser ignorados alguns elementos recolhidos em trabalho recente (Silveirinha e Costa, 2007) que permitem estabelecer diferenças significativas entre os chamados "explicadores domésticos" ("professores que, simultaneamente, lecionam em escolas públicas e dão explicações em casa") e os "explicadores públicos" ("indivíduos que se dedicam à atividade de explicador, mas contratados formalmente pelos centros de explicações"). Tratase de um estudo de caso, cujo âmbito territorial coincide aproximadamente com o de um outro estudo, também citado aqui e realizado pelos autores deste artigo, em que é traçado o perfil dos dois tipos de explicadores.

Em resumo, pode-se afirmar que explicadores domésticos e públicos não se distinguem tanto pelas matérias em que são especialistas (praticamente as mesmas: matemática, física, química etc.), mas antes pelo perfil etário e profissional:

- no grupo dos explicadores domésticos, os autores identificam um perfil dominante de profissionais que têm licenciatura, com uma situação profissional estável, uma média de idade de 58 anos e um tempo de serviço como docentes majoritariamente situado no intervalo entre 25 e 35 anos, e há indícios de que muitos iniciaram sua atividade de explicadores antes de serem docentes. Esses dados parecem revelar, por um lado, a elevada estabilidade e o estatuto que alguns explicadores conseguem conquistar no meio onde desenvolvem a sua atividade profissional como professores da escola pública e como explicadores, circunstância que parece, por outro lado, dispensar muitos deles da necessidade de recorrer à publicidade para atrair clientes uma vez que os alunos parecem ser um dos meios de divulgação mais eficaz;

- no grupo dos explicadores públicos, o trabalho traça um quadro muito diferente do anterior: têm licenciatura, mas apenas pouco mais de metade dos entrevistados tem formação para a docência, sendo

5. O estudo realizado pela Proteste (2006), publicação de uma associação de defesa dos consumidores, parece confirmar que a "tradição" ainda se mantém: "A maioria dos centros [de explicações] contrata professores em atividade". 
em geral um grupo jovem (a maioria entre 26 e 35 anos de idade), sem experiência de ensino e sem vínculos contratuais com escolas do sistema regular, o que seguramente representa uma circunstância potenciadora de seu envolvimento na indústria das explicações, agora num contexto mais organizacional e empresarial que é conferido pelos centros de explicações.

Foi pensando também na situação específica das explicações (mas igualmente em outras, sobretudo as funções docentes exercidas em outros estabelecimentos de ensino e as atividades de formação contínua e profissional) que, em 1999, o governo português decidiu regulamentar a "acumulação de funções públicas e de funções privadas" na área da educação, "e em particular nos ensinos básico e secundário" (Portaria 612/1999, de 14 de agosto).

Salientamos um excerto deste dispositivo legal que resume o essencial da orientação política ao referir que a autorização da acumulação só pode ser concedida quando "a atividade privada a acumular, sendo similar ou de conteúdo idêntico ao das funções públicas desempenhadas pelo requerente, não se dirige aos mesmos destinatários" (grifo nosso).

A primeira idéia a reter é que os professores do ensino público são obrigados a solicitar autorização para poder acumular, por exemplo, a atividade "privada" das explicações; a segunda, a idéia de que a atividade das explicações, exercida pelos professores da escola pública em regime de "acumulação", não pode dirigir-se "aos mesmos destinatários" da sua atividade principal. $\bigcirc$ legislador deixa sem resposta a questão de saber se "os mesmos destinatários" são apenas os alunos das turmas em que o professor-explicador leciona ou se também abrangem todos os alunos da respectiva escola.

Talvez em razão dessa ambiguidade, surge, em 2005, uma nova regra bem mais explícita. $O$ novo enquadramento legal deixa claro que um professor da escola pública não poderá exercer atividade privada, o que inclui as explicações, quando estão envolvidos quer os seus próprios alunos quer quaisquer outros que freqüentem a escola onde leciona:

A autorização de acumulação de funções a que se refere o presente diploma só pode ser concedida verificadas, cumulativamente, as seguintes condições: [...] Se a atividade privada a acumular, em regime de trabalho autônomo ou de 
trabalho subordinado, sendo similar ou de conteúdo idêntico ao das funções públicas desempenhadas pelo requerente, designadamente a prestação de serviços especializados de apoio e complemento educativo, de orientação pedagógica ou de apoio sócio-educativo e educação especial, não se dirija, em qualquer circunstância, aos alunos do agrupamento ou da escola onde o mesmo exerce a sua atividade principal (grifo nosso). (Portaria n. 8|4/2005, de 13 de setembro)

As restrições normativas valem o que valem, como sabemos: valem como mensagem que as autoridades políticas enviam à sociedade, definindo possibilidades e interdições, como é o caso, mas a sua eficácia levanta muitas dúvidas, sobretudo se não forem acompanhadas de medidas complementares que mostrem, por um lado, as vantagens da medida (tarefa complexa tendo em vista a diversidade dos interesses em presença: autoridades, professores, pais, alunos) e, por outro lado, a inequívoca vontade política de tornar conseqüentes as orientações normativas, o que pressupõe rigor e controle.

A análise dos pedidos de "acumulação de funções", recolhidos, tratados e disponibilizados pela Direcção Regional de Educação do Centro - Drec -6 permite leituras pouco abonadoras no que diz respeito aos resultados práticos dessa medida dois anos após sua publicação (2006/2007). Os serviços da administração educativa do centro do território continental registraram 2.549 pedidos de acumulação de funções ${ }^{7}$, num universo de 35.829 professores em serviço na escola pública nesse mesmo ano letivo, de acordo com as estatísticas oficiais da educação (Paredes, 2006, p.29); do total de pedidos, cerca de um quarto (606) era de acumulação de funções no âmbito da atividade privada, situação que contempla as explicações (com 62 pedidos), além de muitas outras

6. O território continental português é organizado em 5 regiões administrativas, a que correspondem várias áreas funcionais (entre as quais a Educação), com o estatuto de serviços descentralizados cuja designação é a de "direção regional", assim distribuídas: Norte, com sede no Porto; Centro, com sede em Coimbra; Lisboa e Vale do Tejo, em Lisboa; Alentejo, com sede em Évora; e Algarve, cuja sede é na cidade de Faro.

7. Os professores em serviço na escola pública podem solicitar a acumulação de funções públicas e privadas, sendo assim possível que um docente subscreva mais do que um pedido de acumulação de funções. Assim, podemos afirmar com segurança que os 2.549 pedidos registados pelos serviços em 2006/2007 corresponderão a um número inferior de docentes, embora não seja possível afirmar quantos, porque essa informação não nos foi fornecida. 
atividades ${ }^{8}$; a título de curiosidade, acrescente-se que há mais nove pedidos que identificam especificamente o local do exercício da actividade como "centro de apoio pedagógico", o que inclui os centros de explicações.

Reportando-nos agora apenas à atividade das explicações, ficamos com uma idéia da distribuição dos pedidos por disciplinas: matemática, 35; física e química, 18; biologia e geologia, 3; língua portuguesa, 2; ciências da natureza, inglês, espanhol, história e geografia de Portugal, todas com I. É interessante assinalar a coincidência registrada entre essa distribuição e a que o nosso estudo registrou quando inquirimos os alunos do $12^{\circ}$ ano de quatro escolas secundárias da cidade Aquarela (Costa et al., 2003).

A análise da distribuição dos pedidos por subregiões (conhecidas em Portugal por "NUT III") permite constatar a grande heterogeneidade de situações, não havendo, em muitos casos, uma relação direta entre o volume de professores em serviço na escola pública e o número de pedidos. Na região Centro, a comparação de 3 das suas sub-regiões permite comprovar essa grande diversidade: o Baixo Vouga, com seus 12 municípios e 5.937 professores, registra cinco pedidos de acumulação, o que mostra um ratio de um pedido para I. I 87 professores; o Baixo Mondego, com 8 municípios e 4.736 professores, soma 13 pedidos, correspondendo a um ratio de um pedido para 364 docentes; o Pinhal Litoral, com 5 municípios e 3.39I professores, assinala 0 pedidos, o que dispensa qualquer comentário9. Verifica-se ainda que, dos 78 municípios abrangidos pela Drec, apenas em 21 (cerca de um quarto) houve pedidos de acumulação de funções para o exercício autônomo da atividade das explicações.

8. As restantes atividades privadas, de acordo com a norma em vigor, são as seguintes: organização de eventos; treinadores e monitores de várias modalidades desportivas; engenharia civil, mecânica e eletrotécnica; arquitetura e design; educação especial em gabinetes técnicopedagógicos; advocacia; mediação de seguros; gestão de empresas; formação profissional e artística; tradução; desenho técnico; animação de tempos livres; consultoria; relações públicas; web design.

9. Caracterização das subregiões (NUT III) indicadas, todas localizadas na região Centro, segundo os municípios que as compõem: i) Baixo Vouga: Águeda, Albergaria-a-Velha, Anadia, Aveiro, Estarreja, Ílhavo, Mealhada, Murtosa, Oliveira do Bairro, Ovar, Sever do Vouga e Vagos; ii) Baixo Mondego: Cantanhede, Coimbra, Condeixa-a-Nova, Figueira da Foz, Mira, Montemoro-Velho, Penacova e Soure; iii) Pinhal Litoral: Batalha, Leiria, Marinha Grande, Pombal e Porto de Mós. 
Esses números apenas revelam a face "oficial" dessa atividade, privada e paralela, desenvolvida por professores da escola pública. Estão longe, cremos mesmo que muito longe, de traduzir o retrato real do exercício da atividade das explicações por parte dos professores da escola pública. Os números mostram, por outro lado, uma evidência: a grande maioria dos professores da escola pública que acumulam funções públicas e privadas não cumpre as exigências legais, conclusão sustentada pelo confronto com a informação do estudo, já referido aqui, de Silveirinha e Costa (2007).

Segundo os autores, na cidade Aquarela, onde estão alocadas 4 escolas secundárias, além de vários agrupamentos de escolas básicas - e vale considerar que apenas as quatro escolas secundárias totalizavam, em 2005/06, 536 docentes $^{10}$ - foram identificados quinze centros de explicações, 5 escolas de línguas e 132 explicadores "domésticos", sendo possível afirmar que uma parte significativa do último grupo de explicadores exerce funções docentes na escola pública. Visto que os dados oficiais da administração educativa reportam para o município da cidade Aquarela (2006/2007) apenas 4 pedidos de acumulação, há sinais de sobra para afirmar que estamos perante uma baixíssima taxa do que se pode chamar de "oficialização" (ou "legalização") da atividade. Além disso, o estudo da Proteste já mencionado mostra que a atividade continua a desenvolver-se informalmente apesar da tentativa de regulação estatal:

Quanto à proibição de os professores do secundário darem explicações a alunos do mesmo agrupamento escolar, nem todos [os explicadores particulares] revelaram conhecimento da lei [...]; A maioria dos centros contrata professores com atividade, mas poucos se importam com a incompatibilidade legal. Menos de metade indicou seguir medidas para evitar que um professor dê explicações a alunos do mesmo agrupamento escolar. (Proteste, 2006)

Chegados a este ponto do nosso trabalho, podemos indagar sobre o que move o poder político, que tem a capacidade reguladora, para se permitir uma regulação com essa baixa taxa de eficácia. Podemos ainda perguntar, na mesma linha de pensamento, o que deu origem ao não cumprimento daquela norma -

10. Dados relativos a 2005/06, disponível em: http://www.giase.min-edu.pt/IndSintese0506.asp; acesso em: 18 abr. 2007. 
os professores, os diretores das escolas, não agem em conformidade por mero desconhecimento da lei? Ou não apresentam pedidos de acumulação de funções guiados por um profundo sentido estratégico, porque sabem que isso significaria a perda de uma parte dos seus clientes por serem justamente alunos da escola em que leccionam, situação proibida à luz da nova orientação? Ou por temerem que a oficialização dessa atividade privada os colocasse sob a mira das autoridades fiscais que não hesitariam em taxar mais essa fonte de rendimentos?

Não temos ainda elementos para responder a estas questões, mas parece confirmar-se, mais uma vez, a aparente facilidade com que as autoridades e os diversos atores assistem ao crônico divórcio entre o plano das normas e o plano das práticas, situação que pode alimentar uma certa idéia de impunidade. Um ex-diretor de uma das escolas secundárias públicas da cidade onde realizamos o nosso estudo garantiu-nos que o empenho dos diretores de escola nesse processo pode ser a chave para o sucesso da medida reguladora porque, assegura, "todos sabem quem são os professores que dão explicações".

Ainda a propósito da regulação, no caso português e sobretudo no estrito plano das orientações, há uma outra dimensão da análise da legislação que pode se revelar rica do ponto de vista da compreensão do fenômeno: que razões poderão mobilizar os governantes a apresentar medidas reguladoras de uma atividade privada, realizada por professores-funcionários públicos, como são as explicações? Procuraremos sistematizá-las de forma breve, recorrendo a um trabalho anterior (Neto-Mendes et al., 2007):

- razões de natureza econômico-financeira, com uma inegável vertente fiscal, como atesta o fato de ambos os diplomas legais serem assinados por responsáveis dos ministérios das Finanças e da Educação - este fato reforça as preocupações que animam os responsáveis pelas políticas a enquadrar, do ponto de vista fiscal, uma atividade que tem uma expressão econômica cada vez mais significativa e que se desenvolve praticamente na clandestinidade;

- razões de natureza profissional, ética e política, típicas de um Estado de direito e de uma democracia ocidental, traduzidas pelo legislador na "necessidade de fomentar a moralização e a transparência" da atividade (Portaria n. 8|4/2005). 


\section{CONSIDERAÇÕES FINAIS}

Pensamos ter sido capazes de evidenciar algumas políticas educacionais cujos efeitos refletem na atividade das explicações, bem como os seus principais instrumentos reguladores - em alguns casos, foi mesmo possível tecer algumas considerações sobre o sucesso ou o fracasso da sua aplicação.

São perceptíveis grandes disparidades nacionais nessa matéria: há governos que não abdicam de atribuir ao Estado um papel central e conseqüente na moralização da atividade, clarificando papéis e atribuições, prevenindo eventuais riscos de corrupção; em outros casos, a proibição das explicações (ou até a rendição ao mais radical laissez-faire que orienta algumas políticas "desregulacionistas") soa a reconhecimento de uma certa incapacidade para regular a atividade e, em uma escala mais ampla, por vezes, seguramente também uma grande dificuldade de avaliar os impactos das políticas educacionais que de alguma forma se cruzam com as explicações (reformas curriculares; política de exames; política de recursos humanos na escola pública; relação entre serviços educacionais privados e públicos, entre outras); há ainda o grupo daqueles países que tendo instrumentos reguladores mínimos - como a obrigatoriedade de os professores da escola pública, que podem ser a grande maioria, como em Portugal, solicitarem autorização para acumular com a atividade privada das explicações ou ainda a proibição de estarem envolvidos nessa atividade alunos das escolas onde aqueles lecionam parecem deixar ao mercado a capacidade quase exclusiva de regulação, intervindo as autoridades apenas reativamente, isto é, quando há qualquer denúncia de irregularidade, recorrendo nesses casos os serviços de inspeção.

Em outro plano, o do estatuto concedido pelo Estado aos serviços privados de explicações, podemos identificar dois grupos de países: o dos que têm como perspectiva uma atividade econômica privada, de caráter essencialmente nacional ou multinacional, reflexo da capacidade empreendedora da sociedade civil e dependente das suas estratégias para atrair clientes, mas sem nenhum vínculo direto com as políticas públicas direcionadas para a educação; e um segundo grupo, seguramente minoritário, que concebe e organiza políticas que, na prática, colocam os serviços privados (eventualmente outros) de explicações como parceiros sociais privilegiados e aliados incontornáveis das políticas públicas nesse domínio, quer através da celebração de contratos-programa, quer através da implementação de uma espécie de "cheque-explicações" que permite às famílias escolher o fornecedor desse serviço para os seus educandos. 
A análise das políticas de regulação das explicações reconhece, de início, o que parece óbvio mas nem sempre é reconhecido: estamos perante uma atividade com forte implantação social, com evidentes conexões com o trabaIho escolar (mas paradoxal e freqüentemente ignoradas ou desvalorizadas por muitos professores e pelas autoridades educacionais), para não falar do seu significativo valor econômico, muitas vezes relegado ao domínio da economia informal. A problemática da crise do Estado e a afirmação de políticas neoliberais são contornos de uma discussão que não pode escamotear a tendência para a "privatização" crescente das responsabilidades, presente quer na tomada de decisão (devolvida às famílias) quer nos encargos mensais que representam as despesas com educação: sabe-se hoje que as explicações representam uma parcela bem significativa dos custos que muitas famílias têm de suportar com a educação dos seus filhos (Ventura, 2006).

O conhecimento da diversidade de fatores que podem estar na origem da procura/oferta de explicações parece indissociável das medidas políticas a desenvolver nesse domínio da regulação das explicações. Sem enveredarmos a priori em julgamentos do tipo "as explicações são uma coisa boa" ou "são uma coisa má" (conhecemos bem a sociedade em que vivemos e as respectivas regras...), pensamos ser urgente um debate sobre as condições e as circunstâncias em que a atividade se desenvolve, os seus impactos ao nível da democratização da educação escolar e da eqüidade. Há sinais preocupantes, na sociedade portuguesa, por exemplo, de elitização do acesso a certas formações de nível universitário, em particular nas áreas da saúde e das artes, e a informação disponível não descarta - pelo contrário, parece sublinhá-la - a importante contribuição das explicações na produção desse fenômeno altamente diferenciador das oportunidades.

\section{REFERÊNCIAS BIBLIOGRÁFICAS}

Boehner, J. No Child Left Behind is working, fact sheet: House Education \& the Workforce Committee, jan. 2005. Disponível em: http://edworkforce.house.gov/issues/I 09th/education/ nclb/nclbworking.htm. Acesso em: I 4 nov. 2005.

BRAY, M. The Shadow education system: private tutoring and its implications for planners. Paris: International Institute for Educational Planning, 1999. Disponível em:http://unesdoc.unesco. org/images/00 I I/00 I I 84/I I 8486e.pdf. Acesso em: 5 dez. 2005. 
COSTA, J. A. et al. $\bigcirc$ Fenômeno das explicações: aspectos da realidade portuguesa e do contexto global. Ensaio, v. I5, n.57, p.475-488, out./dez. 2007.

COSTA, J. A.; VENTURA, A.; NETO-MENDES, A. As Explicações no $12^{\circ}$ ano: contributos para o conhecimento de uma actividade na sombra. Revista Portuguesa de Investigação Educacional, v.2, n.2, p.55-68, 2003.

HALLAK, J.; POISSON, M. Private supplementary tutoring: nature, impact and government responses. In: Sub-Regional Course on: Transparency, Accountability and Anti-Corruption Measures in Education - China, Kazakhstan, Kyrgyzstan, Tajikistan, Uzbekistan: Open Society Institute, International Institute for Educational Planning, 2004. Disponível em: < http://www. unesco.org/iiep/eng/focus/etico/repeng/rep_eng.pdf>. Acesso em: 29 nov. 2005.

Corrupt schools, corrupt universities: what can be done? Paris: International Institute for Educational Planning, Unesco, 2007.

LARTIGUE, C. J.You'll never guess what South Korea frowns upon. Cato Institute, 2006. Disponível em: http://www.cato.org/pub_display.php?pub_id=4679. Acesso em: 2 jan. 2008.

NETO-MENDES, A. Regulação estatal, auto-regulação e regulação pelo mercado: subsídios para o estudo da profissão docente. In: COSTA, J. A.; NETO-MENDES, A.; VENTURA, A. (orgs.). Políticas e gestão local da educação. Aveiro: Universidade de Aveiro, 2004. p.23-33.

et al. La Industria de las clases particulares: de la actividad liberal a la franquicia de las multinacionales. In: SIMPOSIO, 8: Memorias de Pedagogía 2007. La Habana, Cuba, 2007. CD-rom.

PAREDES, A. (coord.). Recenseamento escolar 06/07. Lisboa: Gabinete de Informação e Avaliação do Sistema Educativo do Ministério da Educação, 2006.

PRIMONT, D. F.; DOMAZLICKY, B. Student achievement and efficiency in Missouri Schools and the No Child Left Behind Act. Economics of Education Review, v.25, p.77-90, 2006.

SILVEIRINHA, T.; COSTA, J. A. As Explicações na perspectiva da oferta: alguns dados de um estudo de caso. (Comunicação apresentada no $4^{\circ}$. Congresso Luso-Brasileiro de Política e Administração da Educação/3․ Congresso Nacional do Forum Português de Administração Educacional. 0 Governo das Escolas: os novos referenciais, as práticas e a formação. Lisboa, 2007.)

VENTURA, A. et al. El Fenomeno del apoyo al apredizaje fuera de la escuela visto a través de un análisis comparado. Profesorado: Revista de Curriculum e Formación del Profesorado, v.2, n. I0, 2006. Disponível em: http://www.ugr.es/ recfpro/Revl 02.html. Acesso em: abr. 2008.

Recebido em: maio 2008

Aprovado para publicação em: julho 2008 